EGU21-6519, updated on 06 May 2021

https://doi.org/10.5194/egusphere-egu21-6519

EGU General Assembly 2021

(c) Author(s) 2021. This work is distributed under

the Creative Commons Attribution 4.0 License.

\title{
How do the surface energy fluxes change when a more realistic land cover is included in the WRF model? An evaluation using BLLAST data
}

Carlos Román-Cascón ${ }^{1,2}$, Marie Lothon², Fabienne Lohou², Oscar Hartogensis ${ }^{3}$, Jordi Vila-Guerau de Arellano ${ }^{3}$, David Pino ${ }^{4}$, Carlos Yagüe ${ }^{5}$, and Eric Pardyjak ${ }^{6}$

${ }^{1}$ Centre National d'Études Spatiales (CNES), Laboratoire d'Aérologie, Campistrous, France (carlosromancascon@ucm.es)

2Laboratoire d'Aérologie, CNRS, Université de Toulouse, 31400 Toulouse, France.

${ }^{3}$ Meteorology and Air Quality Section, Wageningen University, Wageningen, Netherlands.

${ }^{4}$ Department of Physics, Universitat Politècnica de Catalunya-BarcelonaTech, 08034 Barcelona, Spain.

${ }^{5}$ Departamento de Física de la Tierra y Astrofísica. Universidad Complutense de Madrid, 28040 Madrid, Spain.

${ }^{6}$ Department of Mechanical Engineering, University of Utah, Salt Lake City, UT, USA

Ideally, numerical weather prediction (NWP) and climate models should include a proper representation of the land surface to correctly simulate the surface energy fluxes and, ultimately, provide successful forecasts of atmospheric variables of common interest for the humans (2-m temperature, 10-m wind speed, relative humidity, etc.). However, in some cases, the issues begin in the first link of this chain, i.e., the surface characteristics included in the model do not represent appropriately the real surface ones in certain areas.

This work investigates how the simulated surface energy fluxes change when the land cover (LC) of an area is improved using a more realistic and higher-resolution dataset. We evaluate the Weather Research and Forecasting (WRF) model simulating a fair-weather day in a heterogeneous area of southern France. Firstly, we use the default LC database in WRF, which differed significantly from the real LC in the area. Secondly, we improve the LC representation of the studied area using a more realistic $1-\mathrm{km}$ dataset prepared by the CESBIO research laboratory. The simulated fluxes were evaluated in a $19 \times 19 \mathrm{~km}$ area with gridded area-averaged fluxes computed using measurements from five eddy-covariance towers deployed over different vegetation types during the Boundary Layer Late Afternoon and Sunset Turbulence (BLLAST) field campaign. The evaluation is done using four land-surface models (LSM) available in WRF (Noah, Noah-MP, CLM4 and RUC).

The results differed depending on the LSM and displayed a high dependency of the simulated fluxes on the specific LC definition within each grid cell. The simulated fluxes improved when a more realistic LC dataset is used except for some LSMs that considered extreme surface parameters for some LC categories (coniferous forest and urban surfaces). Therefore, our findings encourage to check (and improve if needed) the surface representation in the model over the area of analysis, as well as to update surface parameters for some vegetation types. 
